\title{
Sequential Injection Analysis of Ampicillin in Pharmaceuticals by Using Potentiometric Detectors Based on PVC and Sol-Gel Membranes
}

\author{
Nestor Zárate ${ }^{1}$, Alberto N. Araujo ${ }^{2}$, M. Conceiçao B. S. M. Montenegro², Ricardo Pérez-Olmos ${ }^{*}$ \\ ${ }^{1}$ Dpto. Química Analítica, Escuela Universitaria de Ingeniería Técnica Industrial, \\ Universidad del País Vasco, Plaza de la Casilla 3, 48012, Bilbao, \\ ${ }^{2}$ REQUIMTE, Dpto. de Química Física, Faculdade de Farmacia, \\ Universidade do Porto, Rua Anibal Cunha 164, 4050 Porto, Portugal \\ E-mail:qappeolr@lg.ehu.es \\ Received April 1, 2011; revised May 12, 2011; accepted May 26, 2011
}

\begin{abstract}
This work describes the construction and the evaluation of the general performance of new ampicillinate-selective electrodes based on manganese (III) tetraphenylporphyrin [Mn(III) TPP-Cl] as ionophore, incorporated in both PVC and sol-gel membranes and directly applied onto a conductive graphite/epoxy resin support. The units were constructed without inner reference solution adopting conventional configuration and in the case of PVC membrane the tubular configuration was also adopted. The good working characteristics of these electrodes, made possible its application to the determination of ampicillin in pharmaceuticals formulations, both in conventional batch analysis and in flow conditions, when the electrodes were coupled to a SIA system. In the last case the potentiometric sensors presented linear response towards ampicillin concentration between $5.0 \times 10^{-4}$ and $5.0 \times 10^{-2} \mathrm{~mol} \cdot \mathrm{l}^{-1}$ with slopes of -57.4 and $-63.5 \mathrm{mV} \cdot \mathrm{dec}^{-1}$ for the PVC and sol-gel membranes, respectively. The developed procedures enable mean relative standard deviations better than 3\% for all the samples analysed. The obtained results do not statistically differ from those furnished by applying the HPLC reference method.
\end{abstract}

Keywords: Ampicillin, SIA, Potentiometric Detection, Pharmaceutical Formulations

\section{Introduction}

Several PVC membranes based on metalloporphyrins have been used on the construction of selective electrodes for the potentiometric determination of organic species with pharmaceutical interest such us: salicylate [1], penicillin-G [2], valproate [3,4], ibuprofen [5], 2-hydroxybenzyhydroxamate [6] and diclofenac [7]. The use of plasticized PVC membranes for electrodes construction has the disadvantage of the gradual leaching of the plasticizer and the electroactive components from the membrane into the sample solution. This fact deteriorates some sensor characteristics like slope and signal-to-noise ratio, thus limiting the durability of these membranes [8], being this effect more important when the electrode is used in flow conditions. Siloxane polymers are very promising materials for the development of ion-selective membranes by the way of sol-gel technology which have permitted to design hybrid inorganic-organic materials, giving an access to the fabrication of glasses and films of network structure with a controlled porosity and thickness which showed high physical and chemical stability [9]. Sol-gel process has been employed to prepare ISEs selective to chloride $[10,11]$ and copper [12] by using tridodecylmethylammonium chloride and thiosemicarbazone, respectively, as ionophores. Recently, a valproate-selective electrode based on Mn (III)-tetraphenylporphyrin incorporated in a sol-gel matrix was previously reported [4]. Some of these sol-gel sensor membranes were used as potentiometric detectors in FIA [11] and SIA [4] systems.

Ampicillin is one of the most important antibiotics since exerts an effective bactericidal action against both Gram-positive and Gram-negative organisms. Potentiometric determination of ampicillin has been initially carried out by using ISEs sensitive to ampicillinate with 
membranes based on different ionophores such as: quaternary ammonium salts $[13,14]$, ampicillin-phosphotungstate ion pair [15] and azacompounds and metal phtalocyanines [16]. The use of penicillinase have been proposed to construct enzyme electrodes which were applied to the determination of various $\beta$-lactamic antibiotics $[17,18]$. The use of conventional and enzyme potentiometric detectors in pharmaceutical analysis has been receantly reviewed [19,20].

In this work, a novel ampicillinate selective electrode has been constructed and evaluated using the metalloporphyrin [Mn (III)-TPP-Cl]. The solid-contact electrodes were prepared both with PVC and sol-gel membranes, with conventional configuration. In the case of PVC membrane a tubular configuration was also performed. The constructed detectors were coupled to a sequential injection analysis (SIA) system and applied to the analytical control of ampicillin in pharmaceutical formulations (injectables).

\section{Experimental}

\subsection{Reagents and Solutions}

The sensor membrane for both PVC and sol-gel electrodes were prepared using 5,10,15,20 tetrapehenylporphirinate manganese (III) (Mn(III)TPP-Cl) as ionophore. The PVC membrane electrodes consist in a mixture of o-nitrophenyloctylether (o-NPOE) as plasticizer, and high molecular weight PVC as inert matrix, previously dissolved in tetrahydrofuran. The sol-gel membrane electrodes were prepared using methyltrietoxysilane (MTES), as silanol precursor, ethanol, hydrochloric acid and polyethyleneglycol (PEG 6000), for avoiding a fast membrane drying, and deionized water. The conductive support, in both electrodes, was a mixture $(1: 1.2 \mathrm{w} / \mathrm{w})$ of graphite powder and a non-conductive epoxy resin (Araldite $\mathrm{M}$ and hardener $\mathrm{HY}$ ) respectively.

For the PVC electrodes, the stock solution used to prepare the calibration curves in the potentiometric determinations was a $1.0 \times 10^{-1} \mathrm{~mol} \cdot \mathrm{l}^{-1}$ sodium ampicillin prepared in a $5.0 \times 10^{-2} \mathrm{~mol} \cdot \mathrm{l}^{-1}$ dihydrogenphosphate solution ( $\mathrm{pH} 4.5$ ). In the case of the sol-gel electrodes, the sodium ampicillin stock solution was dissolved in a $1.0 \times 10^{-2} \mathrm{~mol} \cdot \mathrm{l}^{-1}$ morpholinoethanesulfonic acid solution ( $\mathrm{pH}$ 3.8). These ampicillin stock solutions were prepared daily because of its instability.

The $5.0 \times 10^{-2} \mathrm{~mol} \cdot \mathrm{l}^{-1}$ dihydrogenphosphate solution was used for the ionic strength and $\mathrm{pH}$ adjustment and also as carrier solution in the potentiometric determination with PVC membrane electrodes in flow conditions. Besides the outer chamber of the double junction reference electrode was filled up with the above mentioned solution. In the case of the sol-gel membrane electrodes the $1.0 \times 10^{-2}$ morpholinoethanesulfonic acid solution was used for the ionic strength and $\mathrm{pH}$ adjustment, as carrier solution and also for filling up the outer chamber of the double junction reference electrode. Both ISA/ carrier solutions contained $1.0 \times 10^{-8} \mathrm{~mol} \cdot \mathrm{l}^{-1}$ sodium ampicillin for the rapid reestablishment of the potentiometric baseline.

For the chromatographic assays the mobile phase A consists in: $0.5 \mathrm{ml}$ of diluted acetic acid solution (1.2 $\mathrm{g}$ of glacial acetic acid in $10 \mathrm{ml}$ of deionized water), $50 \mathrm{ml}$ of a $2.0 \times 10^{-1} \mathrm{~mol} \cdot \mathrm{l}^{-1}$ dihydrogenphosphate solution and $50 \mathrm{ml}$ of acetonitrile was made up to $1000 \mathrm{ml}$ with deionized water. Mobile phase B was prepared in the same way than mobile phase A but in this occasion $400 \mathrm{ml}$ of acetonitrile were added. Both mobile phases were degasified and filtered through a Millipore $0.45 \mu \mathrm{m}$ filter.

All solutions were prepared with distilled and deionized water with conductivity less than $0.1 \mu \mathrm{S} \cdot \mathrm{cm}^{-1}$, and analytical grade reagents were used without any additional purification.

\subsection{Apparatus}

Potentiometric measurements were carried out by using a Crison 2002 potentiometer (sensitivity $\pm 0.1 \mathrm{mV}$ ) coupled to an electrode switcher, of the same brand, that recorded the potential difference between an Orion Research 92-02-00 double junction reference electrode and the corresponding indicator electrode. To determine the $\mathrm{pH}$ value of all solutions an Orion Research 91-02-00 combined glass electrode was used.

In constructing the SIA system (Figure 1), a Gilson Minipulse 3 four-channel peristaltic pump was used to ensure flow of the solutions. A CheminertTM C25-3 $188 \mathrm{D}$ multiposition rotatory valve of 8 ports, electrically actuated, was used to select an adequate solution. With the purpose of guaranteeing the maximum reproducibility of the aspirated and forward volumes, an NResearch 161 T031 three-way solenoid valve (SV) was placed between the peristaltic pump and the selection valve. All of the SIA system components were connected with PTFE tubes (i.d. $0.8 \mathrm{~mm}$ ). The reaction coil was $50 \mathrm{~cm}$ in length and the holding coil was $200 \mathrm{~cm}$ and was coiled over a plastic net. The selective and the reference electrodes were fitted in home-made plastic supports constructed as described elsewhere [21] with slight modifications. With the aim of eliminating electric noise, the constructed electrodes were connected to a home-made ground electrode [22]. For the data adquisition a single channel Kipp\&Zonen BD11 stripchart recorder was used. All the SIA system operations were controlled by a computer through an Advantech 


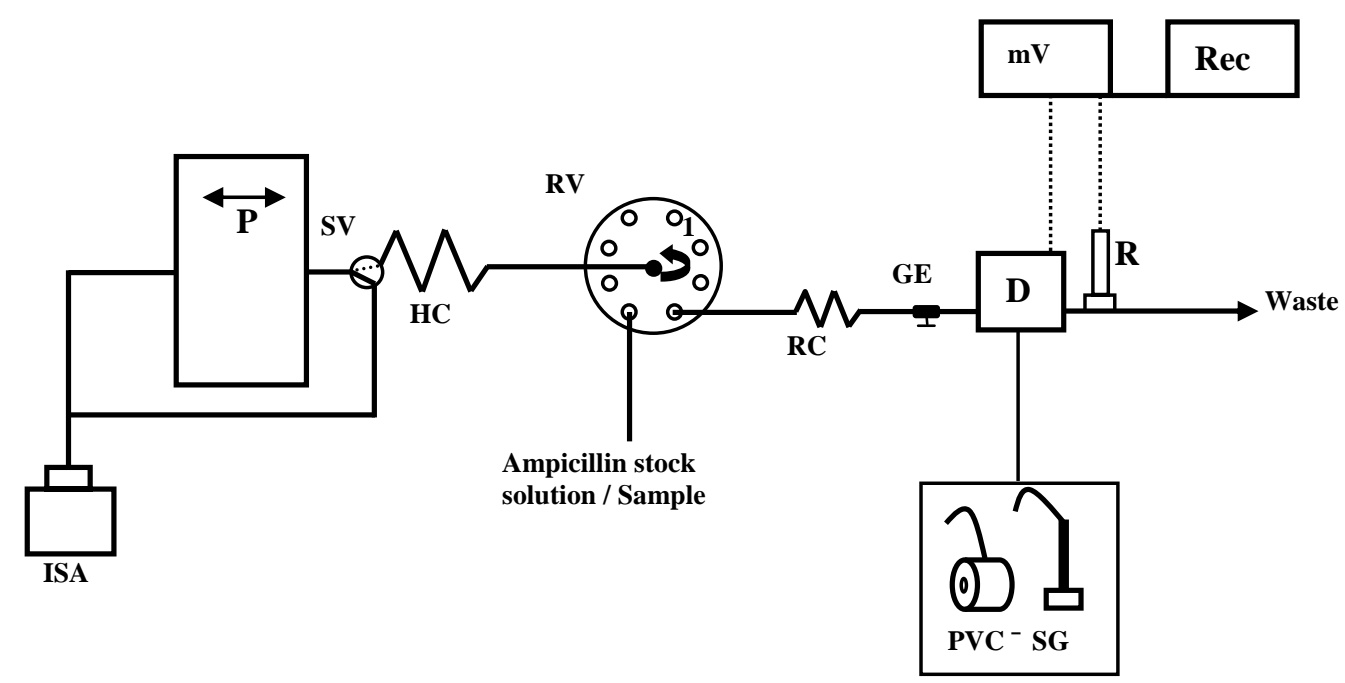

Figure 1. Schematic representation of the potentiometric SIA system developed. P: peristaltic pump; RV: Multiposition rotatory valve; SV: Three-way solenoid valve; HC: Holding coil; RC: reaction coil; GE: Ground electrode; D: PVC or sol-gel membrane.

PCL-711S interface card by running software written in Quick Basic 4.5 programming language.

The liquid chromatography equipment used for the ampicillin determinations was a model Hewlett-Packard (1050 series) with a Hewlett-Packard (1040M series II DAD) as detector, and a Spherisorb ODS2 $(250 \times 4 \mathrm{~mm})$, $5 \mu \mathrm{m}$ particle size, column from Teknochroma. For the equipment control and data acquisition a ChemStation, from Agilent Technologies, was used.

\subsection{Construction of the Electrodes}

The PVC membrane for the ampicillin selective electrodes, of conventional configuration, were prepared as previously reported [23] by using $\mathrm{Mn}(\mathrm{III}) \mathrm{TPP}-\mathrm{Cl}$ (1 wt\%) as an ionophore, o-NPOE (66 $\mathrm{wt} \%$ ) as plasticizer solvent and PVC (33 wt\%), previously dissolved in tetrahydrofuran, as polymeric matrix. The membranes were applied dropwise over the graphite conductive support and dried at room temperature overnight. The tubular PVC detectors were constructed as described elsewhere [24] using the same membrane composition.

The sol-gel membranes were prepared as previously reported [4], with slight modifications, by mixing $4.5 \mathrm{ml}$ of alcoxy reagent (MTES), $1.5 \mathrm{ml}$ double-deionized water, $1.0 \mathrm{ml}$ ethanol and $100 \mu \mathrm{l}$ of a $1.0 \times 10^{-1} \mathrm{~mol} \cdot \mathrm{l}^{-1}$ hydrochloric acid solution, in a $50.0 \mathrm{ml}$ PTFE beaker. After well-mixing, $25.0 \mathrm{mg}$ of $\mathrm{Mn}$ (III)TPP-Cl was added to the solution followed by $50 \mu \mathrm{l}$ of PEG 6000 which avoided fast membrane drying and consequent brittleness. This mixture was left overnight under stirring until the sol-gel solution was achieved and then the conductive graphite surface was immersed into the viscous solution for $5 \mathrm{~s}$.
The obtained membranes were dried at $20^{\circ} \mathrm{C}$ for five days.

\subsection{Procedures}

\subsubsection{Sample Preparation}

Pharmaceutical formulation samples (injectables), containing sodium ampicillin, were prepared by rigorous weighing out of $200.0 \mathrm{mg}$ of the solid and subsequent dissolution in $100.0 \mathrm{ml}$ of a $5.0 \times 10^{-2} \mathrm{~mol} \cdot \mathrm{l}^{-1}$ dihydrogen phosphate or $1.0 \times 10^{-2} \mathrm{~mol} \cdot \mathrm{l}^{-1}$ morpholinoethanesulfonic acid (HMES) solutions when the PVC membrane or the sol-gel membrane electrodes were respectively used. All the samples were prepared to have a final ampicillin concentration that fitted in the linear concentration range of the developed electrodes.

\subsubsection{Developed Batch Procedure}

An aliquot of $50.0 \mathrm{ml}$, of the prepared ampicillin sample, was pipetted directly into a $150 \mathrm{ml}$ beaker and the PVC or sol-gel membrane electrodes and the reference electrode were immersed in the magnetic stirred solution. Finally, the sample concentration was determined by means of direct potentiometry using calibration curves prepared with ampicillin concentration ranging from 1.0 $\times 10^{-4}$ to $1.0 \times 10^{-2} \mathrm{~mol} \cdot \mathrm{l}^{-1}$.

\subsubsection{Developed SIA Procedure}

Once the SIA system had been set up, all the PTFE tubes were filled with the carrier/ISA solution placing the peristaltic pump in the propulsion mode. This operation mode was maintained until a stable baseline for the potentiometric detector was obtained. The ampicillin solu- 
tions, of the calibration curve, $5.0 \times 10^{-4}, 1.0 \times 10^{-3}, 5.0$ $\times 10^{-3}, 1.0 \times 10^{-2}$ and $5.0 \times 10^{-2} \mathrm{~mol} \cdot \mathrm{l}^{-1}$ were prepared from the $1.0 \times 10^{-1} \mathrm{~mol} \cdot \mathrm{l}^{-1}$ sodium ampicillin stock solution. Only two steps were required for getting the analytical signal and they were applied to each solution. When the PVC membrane electrodes were used, $165 \mu 1$ of ampicillin stock solution were aspirated through port 5 of the rotatory valve at a flow of $1.3 \mathrm{ml} \cdot \mathrm{min}^{-1}$ and sent to the detector through port 6 at a flow rate of $1.5 \mathrm{ml} \cdot \mathrm{min}^{-1}$. However, when the sol-gel membrane electrodes were employed, $250 \mu \mathrm{l}$ of ampicillin stock solution were aspirated and sent to the detector at the aforementioned flow rates. The pharmaceutical samples suffered the same procedure.

\subsubsection{Reference Procedure}

The HPLC method used for the determination of ampicillin in the pharmaceutical samples was similar to the chromatographic method proposed by the European Pharmacopoeia [25]. Therefore, $30.0 \mathrm{mg}$ of solid sample were rigorous weighed and dissolved in $10 \mathrm{ml}$ of mobile phase (A/B), formed by $75 \%$ of mobile phase A and $25 \%$ of mobile phase B. From this solution, $0.1 \mathrm{ml}$ were exactly pipetted and transferred to a $25.0 \mathrm{ml}$ volumetric flask and diluted with the mobile phase. Afterwards, an aliquot of $20 \mu \mathrm{l}$ from this solution was injected into the HPLC equipment. The separation and detection were carried out according to the following chromatographic conditions: elution mode, isocratic; flow rate, $1.0 \mathrm{ml}$ min-1; detection wavelength, $254 \mathrm{~nm}$; temperature, ambient; retention time expected, $3.32 \mathrm{~min}$; analysis time, $5.5 \mathrm{~min}$.

\section{Results and Discussion}

\subsection{Working Characteristics of Electrodes with Conventional Configuration}

In order to determine the influence of the immobilizing support on the performance of the electrodes selective to ampicillinate, the metalloporphyrin $\mathrm{Mn}(\mathrm{III})-\mathrm{TPP}-\mathrm{Cl}$ was incorporated both into PVC or ceramic (sol-gel) membranes. The working characteristics of both types of conventional electrodes constructed were evaluated on the basis of the IUPAC recommendations [26]. The experiments were performed in solutions with the ionic strength adjusted with the $5.0 \times 10^{-2} \mathrm{~mol} \cdot \mathrm{l}^{-1}$ dihydrogenphosphate solution when the PVC membranes were evaluated or with the $1.0 \times 10^{-2} \mathrm{~mol} \cdot \mathrm{l}^{-1}$ HMES solution in the case of sol-gel membranes. From the data, presented in Table 1, it is possible to affirm that both types of ampicillinate selective electrodes constructed in this work, using the same ionophore, presented similar or better slopes, reproducibilities, response times and practical limits of detection than those reported by other authors [13-16]. In spite of having better reproducibility and similar response time, the sol-gel membrane electrode showed narrower linear concentration range and shorter life time when compared with that obtained with PVC membrane electrode.

The Reilley diagrams obtained for the PVC membrane electrode evidenced an operational $\mathrm{pH}$ range between 3.5 and 8.0 for the higher concentration of ampicillinate (1.0 $\left.\times 10^{-2} \mathrm{~mol} \cdot \mathrm{l}^{-1}\right)$ tested; however, for lower concentration of ampicillinate $\left(1.0 \times 10^{-4} \mathrm{~mol} \cdot \mathrm{l}^{-1}\right)$, the operational $\mathrm{pH}$ range clearly diminishes, mainly in the basic zone. This is probably due to the fact that with an increase of OHrelatively to ampicillinate, the response towards this ion overlaps the response towards the primary ion. Similar behaviours has been previously described when PVC membranes electrodes selective to other organic compounds, using the same metallporphyrin, were constructed and evaluated by some of us $[2,4,27]$. For that reason the working $\mathrm{pH}$ chosen for all measurement condition was 4.5 which guaranteed, according to the penicillin $\mathrm{pKa}(2.5)$ the complete dissociation of the analyte. In the case of sol-gel membrane electrodes, the Reilley diagrams showed that the potential measurements of the electrode changed according to the $\mathrm{pH}$ of the ampicillinate solution. This fact previously reported [28], was due to the presence of silanol groups ( $\mathrm{Si}-\mathrm{OH})$ at the surface of the ceramic membrane which makes these materials sensitive to $\mathrm{pH}$ changes. So, when this type of electrode was used, a strict control of sample pH (3.8) was needed.

Interference caused by some common inorganic anions was evaluated by carrying out the determination of the selectivity potentiometric coefficients (log Kpot) by the separate solution method at $\mathrm{pH} 4.5$ and 3.8 for the $\mathrm{PVC}$ and sol-gel membranes respectively, and in the concentration range from $1.0 \times 10^{-4}$ to $1.0 \times 10^{-2} \mathrm{~mol} \cdot \mathrm{l}^{-1}$ for both primary and interfering ions. The results showed in Table 1 were obtained after two determinations performed with three electrodes and reveal that the developed electrodes were fairly selective to ampicillinate over other anions, being their selectivity coefficients similar or better than those obtained by other authors $[13,16]$. Regarding the Hofmeister selectivity pattern of the classical liquid ion-exchanger, the developed PVC and sol-gel membranes exhibited different selectivity sequences from that one as previously demonstrated when the same metalloporphyrin had been used to construct other anion selective membrane electrodes, namely carboxylic ions $[2,4,27]$. For PVC membrane electrode the sequence $\mathrm{SCN}^{-}>\mathrm{Sal}^{-}>\mathrm{I}^{-}>\mathrm{NO}^{3-}>\mathrm{NO}^{2-}>\mathrm{Cl}^{-}>$ $\mathrm{SO}_{4}{ }^{2-}>\mathrm{H}_{2} \mathrm{PO}_{4}^{-}>\mathrm{HCO}^{3-}$ was obtained. Regarding the sol-gel membrane electrode the sequence $\mathrm{HCO}^{3-}>\mathrm{NO}^{2-}>$ $\mathrm{NO}^{3-}>\approx \mathrm{SCN}^{-}>\mathrm{Sal}^{-}>\mathrm{I}^{-}>\mathrm{Cl}^{-}>\mathrm{H}_{2} \mathrm{PO}_{4}^{-}>\mathrm{SO}_{4}{ }^{2-}$ was 
Table 1. General working characteristics of the developed ampicillinate selective electrodes.

\begin{tabular}{|c|c|c|}
\hline Characteristics & PVC membrane & Sol-gel membrane \\
\hline Linear concentration range $\left(\mathrm{mol} \cdot 1^{-1}\right)$ & $1.7 \times 10^{-5}-1.0 \times 10^{-1}$ & $1.5 \times 10^{-4}-1.0 \times 10^{-1}$ \\
\hline Practical limit of detection $\left(\mathrm{mol} \cdot \mathrm{l}^{-1}\right)$ & $1.0 \times 10^{-4}$ & $1.0 \times 10^{-3}$ \\
\hline Slope $\left(\mathrm{mV} \cdot\right.$ decade $\left.^{-1}\right)$ & $60.2 \pm 0.8$ & $65.3 \pm 0.3$ \\
\hline Potential stability $\left(\mathrm{mV} \cdot\right.$ day $\left.^{-1}\right)$ & \pm 1.5 & \pm 0.7 \\
\hline Response time (seconds) & $<10$ & $<10$ \\
\hline Lifetime (months) & 10 & 1 \\
\hline Working $\mathrm{pH}$ range $\mathrm{e}^{\mathrm{a}}$ & $3.0-7.5$ & - \\
\hline $\begin{array}{l}\text { Potentiometric selectivity coeffi- } \\
\text { cients }^{\text {a }}\left(\log K^{\text {pot }}\right)\end{array}$ & PVC membrane & Sol-gel membrane \\
\hline Sulphate & $-1.37 \pm 0.02$ & $-1.38 \pm 0.06$ \\
\hline Dihydrogenphosphate & $-1.40 \pm 0.03$ & $-1.32 \pm 0.05$ \\
\hline Hydrogencarbonate & $-1.65 \pm 0.02$ & $0.04 \pm 0.04$ \\
\hline Chloride & $-0.41 \pm 0.01$ & $-0.65 \pm 0.05$ \\
\hline Nitrate & $-0.43 \pm 0.03$ & $-0.42 \pm 0.14$ \\
\hline Nitrite & $-0.22 \pm 0.01$ & $0.12 \pm 0.08$ \\
\hline Iodide & $0.68 \pm 0.04$ & $-0.45 \pm 0.03$ \\
\hline Thiocyanate & $1.62 \pm 0.07$ & $-0.17 \pm 0.07$ \\
\hline Salicylate & $1.45 \pm 0.06$ & $-0.22 \pm 0.27$ \\
\hline
\end{tabular}

a. Ampicillinate concentration $=1.0 \times 10^{-3} \mathrm{~mol} \cdot \mathrm{l}^{-1}$

obtained. Being much more hydrophilic in nature, the sol-gel membrane was less affected by lypophilic anions such as $\mathrm{SCN}^{-}$which confirm the notion that interferent action can be reduced by eliminating the plasticizer in the polymeric membrane [29]. On the other hand, the fact that the interferent action of the salicilate diminished when the sol-gel membrane electrode is used, could led to eliminate significant error for measurement of ampicillin in biological fluid samples from patients who have ingested aspirin.

\subsection{Behaviour of the Electrodes in the SIA System}

Both type of constructed electrodes were evaluated when they were coupled in the SIA system depicted in Figure 1 using a $5.0 \times 10^{-2} \mathrm{~mol} \cdot \mathrm{l}^{-1}$ dihydrogenphosphate and a $1.0 \times 10^{-2} \mathrm{~mol} \cdot \mathrm{l}^{-1}$ HMES solutions as carriers for electrodes with PVC or sol-gel membranes, respectively. Initially, the aspiration and propulsion flow rates were estimated by interpolation in graphs obtained by plotting $\mathrm{ml} \cdot \mathrm{min}^{-1}$ vs. revolution per minute (rpm) of the peristaltic pump. The intensity and repeatability of the potentiometric signals obtained were studied either by varying the injection volume of the ampicillinate solution in the interval $115-450 \mu \mathrm{l}$, and the propulsion rate in the in- terval $1.2-3.5 \mathrm{ml} \cdot \mathrm{min}^{-1}$ in a way, whereby the sampling rate was not diminished. With the increase of the injection volume, an increase in the magnitude of analytical signals was verified up to volumes of 165 and $250 \mu \mathrm{l}$ for PVC and sol-gel membrane electrodes respectively. For greater injection volumes no significant improvement in the signals magnitude was observed requiring more time and greater consumption of reagents. It was also observed that volumes smaller than 165 and $250 \mu \mathrm{l}$ provided higher dispersion of the sample zone and consequently lack of linearity. These injection volumes were obtained for a maximum flow rate of $1.5 \mathrm{ml} \cdot \mathrm{min}^{-1}$ for both potentiometric detectors. The increments in the flow rate carried an appreciable loss of signal repeatability, possibly caused by inertia to the flow during the aspiration stage, and by the dynamic response characteristics of each electrode type used [30].

The general working characteristics of both electrodes were evaluated by means of calibration curves obtained for a range between $1.0 \times 10^{-6}$ and $1.0 \times 10^{-1} \mathrm{~mol} \cdot \mathrm{l}^{-1}$ and they appear reflected in Table 2. From these data, it is possible to state that sol-gel membrane electrode showed narrower linear concentration range and lower life-time than PVC membrane electrode, but the slope resulted to be higher. When compared the behaviour of these units with the results obtained in batch conditions, a small nar- 
Table 2. Figures of merit of the developed potentiometric SIA system.

\begin{tabular}{|c|c|c|}
\hline & PVC membrane & Sol-gel membrane \\
\hline Linear concentration range $\left(\mathrm{mol}^{-1} \mathrm{l}^{-1}\right)$ & $7.0 \times 10^{-5}-1.0 \times 10^{-1}$ & $7.5 \times 10^{-4}-1.0 \times 10^{-1}$ \\
\hline Practical limit of detection $\left(\mathrm{mol} \cdot \mathrm{l}^{-1}\right)^{\mathrm{b}}$ & $4.0 \times 10^{-5}$ & $4.1 \times 10^{-4}$ \\
\hline Regression equation $^{\mathrm{a}}$ & $E=-57.4 \log [C]+20.1$ & $E=-63.5 \log [C]+19.3$ \\
\hline Quadratic correlation coefficient $\left(\mathrm{R}^{2}\right)$ & 0.9992 & 0.997 \\
\hline $\begin{array}{l}\text { Electrode slope and standard deviation } \\
\qquad\left(\mathrm{mV} \cdot \mathrm{decade}^{-1}\right)\end{array}$ & $-57.4 \pm 0.5$ & $-63.5 \pm 0.5$ \\
\hline Relative standard deviation $(\%)^{\mathrm{c}}$ & 0.2 & 0.3 \\
\hline Sampling rate $\left(\right.$ sample $\left.\mathrm{h}^{-1}\right)$ & 40 & 33 \\
\hline
\end{tabular}

rowing in the linear concentration ranges, an increase in the practical limit of detection and a diminution of the slopes were observed with both type of electrodes.

\subsection{Analytical Applications}

The potentiometric analysis of five samples of pharmaceutical formulation (injectables) containing sodium ampicillin, commercialized in Europe, was carried out with conventionally or tubular (PVC membranes) shaped electrodes according to the batch and SIA procedures. For comparison purposes the samples were simultaneously analyzed by applying the HPLC reference method and the obtained results are summarized in Tables 3 and 4.

The precisions of the developed and the reference methods were evaluated by their simultaneous application to 6 different samples of the same pharmaceutical product and were expressed in terms of their relative standard deviations. From the obtained data, it was possible to affirm that the precisions of both, batch and SIA, potentiometric determinations were good since the mean relative standard deviation were $1.7 \%$ (PVC membrane electrode) and $1.2 \%$ (sol-gel membrane electrode) in the SIA system and 2.1 and $1.6 \%$ respectively in batch conditions. To test whether the developed (batch and SIA) and the reference methods differed in their precision, a significance (two-tailed) F-test was carried out. Since the calculated $\mathrm{F}$ values were (just with one exception) less than the critical $F$ value (7.15), there was no statistically significant difference between the standard deviations at 95\% confidence level [31]. After three additions of known concentration of standard sodium ampicillin, the samples were analysed following the same methods and the percentages of spike recovery calculated were used to evaluate the accuracy. No significant differences were found between the obtained results by applying batch or SIA procedures. Moreover, slight better results were founded when sol-gel membrane electrode, instead of PVC membrane electrode, was used.

On the other hand, when the ampicillin commercial samples were simultaneously analyzed by applying the developed potentiometric, batch and SIA, and the HPLC reference method, a very slight tendency to get lower values with the potentiometric methods was observed, since the mean percentage of difference were $-1.3 \%$ for the PVC membrane electrode and $-1.1 \%$ for the sol-gel membrane electrode in batch conditions and $-0.8 \%$ for both type of membrane electrodes when used as potentiometric detectors in the SIA system. In order to establish whether the developed potentiometric methods could be accepted as giving reliable results, a two-tailed t-test with multiple sample (paired by differences) was performed at a $\mathrm{P}=0.05$ confidence level. The $\mathrm{t}$-data paired test was applied using the formula: $t_{\text {calc. }}=\bar{x}_{D} \frac{\sqrt{n}}{S_{X}}$, where $\bar{x}_{\mathrm{D}}$ is the mean difference between the methods and $S_{x}$ is the standard deviation of the differences. When substituting for tcalc., they were found to be -0.62 (PVC membrane electrode) and -1.11 (sol-gel membrane electrode) in the flow system, and -0.79 and -1.19 respectively in batch analysis. Since all these values were less than the tabulated $t$-value (2.78) there was no statistically significant difference between both potentiometric determinations and the HPLC reference method [31].

The limits of detection of the developed potentiometric procedures were established according to the Analytical Methods Committee [32] and following the criteria $(\bar{x}+$ $3 \sigma$ blank). The calculated values resulted to be $80.5 \mathrm{mg} \cdot \mathrm{l}^{-1}$ for the PVC membrane electrode and $88.2 \mathrm{mg} \cdot \mathrm{l}^{-1}$ for the sol-gel membrane electrode when used as potentiometric detectors in flow analysis, and 71.7 and $83.8 \mathrm{mg} \cdot \mathrm{l}^{-1}$ respectively in batch conditions. The limits of quantification $(x+10 \sigma$ blank $)$ were found to be $81.7 \mathrm{mg} \cdot l^{-1}$ for the PVC membrane electrode and $90.1 \mathrm{mg} \cdot 1^{-1}$ for the sol-gel membrane electrode when used in the SIA system, and 79.8 and $93.7 \mathrm{mg} \cdot 1^{-1}$ respectively in batch analysis.

\section{Conclusions}

The study undertaken has demonstrated that the use of $\mathrm{Mn}$ (III) TPP-Cl as an ionophore for the preparation of 
Table 3. Ampicillinate determination in injectables by simultaneous application of the developed SIA and reference HPLC methods.

\begin{tabular}{|c|c|c|c|c|c|c|c|c|c|c|c|c|}
\hline & \multicolumn{2}{|c|}{$\begin{array}{c}\text { Reference HPLC } \\
\text { method }\end{array}$} & \multicolumn{10}{|c|}{ Developed SIA method } \\
\hline & & & \multicolumn{5}{|c|}{ PVC membrane } & \multicolumn{5}{|c|}{ Sol-gel membrane } \\
\hline Sample & $\mathrm{X}^{\mathrm{a}}$ & $\mathrm{RSD}^{\mathrm{b}}$ & $\mathrm{X}^{\mathrm{a}}$ & $\mathrm{RSD}^{\mathrm{b}}$ & $\mathrm{R}^{\mathrm{c}}$ & $\mathrm{RE}^{\mathrm{d}}$ & $\mathrm{F}^{\mathrm{e}}$ & $\mathrm{X}^{\mathrm{a}}$ & $\mathrm{RSD}^{\mathrm{b}}$ & $\mathrm{R}^{\mathrm{c}}$ & $R E^{d}$ & $\mathrm{~F}^{\mathrm{e}}$ \\
\hline Gobemicina & $\begin{array}{c}946.4 \pm \\
12.2\end{array}$ & 1.3 & $972.9 \pm 21.4$ & 2.2 & 98.1 & 4.6 & 3.08 & $971.7 \pm 10.8$ & 1.1 & 99.3 & 2.6 & 1.27 \\
\hline Britapen & $\begin{array}{c}1028.4 \pm \\
8.6\end{array}$ & 0.8 & $997.5 \pm 12.9$ & 1.3 & 99.5 & -3.0 & 2.25 & $1020.7 \pm 18.8$ & 1.8 & 101.2 & -0.7 & 4.78 \\
\hline Hiperbiótico & $981.7 \pm 7.0$ & 0.7 & $1008.9 \pm 10.2$ & 1.0 & 102.7 & 2.8 & 2.12 & $962.7 \pm 6.7$ & 0.7 & 103.6 & -1.9 & 1.09 \\
\hline Unacim & $\begin{array}{c}1050.2 \pm \\
7.9\end{array}$ & 0.7 & $1023.9 \pm 18.0$ & 1.8 & 100.3 & -2.5 & 5.19 & $1031.2 \pm 11.6$ & 1.1 & 100.8 & -1.8 & 2.15 \\
\hline Amplital & $\begin{array}{c}1034.8 \pm \\
9.2\end{array}$ & 0.9 & $998.6 \pm 21.0$ & 2.1 & 98.2 & -3.5 & 5.21 & $1010.6 \pm 15.4$ & 1.5 & 101.0 & -2.3 & 2.80 \\
\hline
\end{tabular}

Table 4. Ampicillinate determination in injectables by simultaneous application of the developed batch and reference HPLC methods.

\begin{tabular}{|c|c|c|c|c|c|c|c|c|c|c|c|c|}
\hline & \multicolumn{2}{|c|}{$\begin{array}{c}\text { Reference HPLC } \\
\text { method }\end{array}$} & \multicolumn{10}{|c|}{ Batch method } \\
\hline & & & \multicolumn{5}{|c|}{ PVC membrane } & \multicolumn{5}{|c|}{ Sol-gel membrane } \\
\hline Sample & $\mathrm{X}^{\mathrm{a}}$ & $\mathrm{RSD}^{\mathrm{b}}$ & $\mathrm{X}^{\mathrm{a}}$ & $\mathrm{RSD}^{\mathrm{b}}$ & $\mathrm{R}^{\mathrm{c}}$ & $\mathrm{RE}^{\mathrm{d}}$ & $\mathrm{F}^{\mathrm{e}}$ & $\mathrm{X}^{\mathrm{a}}$ & $\mathrm{RSD}^{\mathrm{b}}$ & $\mathrm{R}^{\mathrm{c}}$ & $\mathrm{RE}^{\mathrm{d}}$ & $\mathrm{F}^{\mathrm{e}}$ \\
\hline Gobemicina & $946.4 \pm 12.2$ & 1.3 & $963.6 \pm 11.8$ & 1.2 & 97.1 & 1.8 & 1.07 & $939.4 \pm 10.8$ & 1.1 & 98.9 & -0.7 & 1.28 \\
\hline Britapen & $1028.4 \pm 8.6$ & 0.8 & $990.3 \pm 20.8$ & 2.1 & 98.6 & -3.7 & 5.84 & $1008.9 \pm 14.1$ & 1.4 & 101.7 & -1.9 & 2.70 \\
\hline Hiperbiótico & $981.7 \pm 7.0$ & 0.7 & $1014.1 \pm 17.2$ & 1.7 & 100.2 & 3.3 & 6.06 & $1010.2 \pm 13.1$ & 1.3 & 103.1 & 2.9 & 3.50 \\
\hline Unacim & $1050.2 \pm 7.9$ & 0.7 & $1005.1 \pm 29.4$ & 2.8 & 97.7 & -4.3 & 13.85 & $1011.3 \pm 20.2$ & 2.0 & 100.9 & -3.7 & 6.55 \\
\hline Amplital & $1034.8 \pm 9.2$ & 0.9 & $998.6 \pm 25.0$ & 2.5 & 98.3 & -3.5 & 7.38 & $1011.0 \pm 22.2$ & 2.2 & 103.8 & -2.3 & 5.84 \\
\hline
\end{tabular}

PVC and sol-gel membranes can give rise to electrodes with good working characteristics for ampicillinate anion, which enables the development of a potentiometric method for its determination in pharmaceutical formulations. The quality of the obtained results, by using the developed potentiometric methods, is similar to those furnished by applying the HPLC reference method, being the attained results slightly better when the sol-gel membrane electrode is used.

On the other hand, the fact that the electrodes can be easily constructed and incorporated in a SIA system, showing good performances, offers some advantages respectively to the batch determination such us: the sys- tem is easy to operate, the solution handling operations are reduced, and the proposed method is less time consuming with a significant reduction of reagents consumption and waste generation. Besides, the instrumentation is cheaper when compared with the cost of the equipment required in the HPLC reference method, which justify the use of potentiometry as an alternative analytical technique for the determination of ampicillin in pharmaceutical products.

\section{Acknowledgements}

This work was supported by the University of the Basque 
Country (Spain) through Project UPV 171.363-E-15923/ 2004. One of the authors (N.Z.) wishes to thank to this University for the Ph.D. Grant 98/13828/01. We also thank to Laboratorios Normon S.A, Madrid (Spain), for samples kindly provided.

\section{References}

[1] E. Malinowska, J. Niedziólka, E. Rozniecka and M. E. Meyerhoff, "Salicylate-Selective Membrane Electrodes Based on $\mathrm{Sn}(\mathrm{IV})$ and $\mathrm{O}=\mathrm{Mo}(\mathrm{V})$-Porphyrin: Differences in Response Mechanism and Analytical Performance," Journal of Electroanalytical Chemistry, Vol. 514, No. 1-2, 2001, pp. 109-117. doi:10.1016/S0022-0728(01)00615-5

[2] E. M. G. Santos, A. N. Araújo, C. M. C. M. Couto, M. C. B. S. M. Montenegro, A. Kejzlarová and P. Solich, "Ion Selective Electrodes for Penicillin-G Based on Mn (III) TPP-Cl and Their Application in Pharmaceutical Formulations by Sequential Injection Analysis," Journal of Pharmaceutical and Biomedical Analysis, Vol. 36, No. 4, 2004, pp. 701-709. doi:10.1016/j.jpba.2004.08.006

[3] T. Katsu, K. Ido, A. Moriya, Y. Nakae and I. Sakata, "Valproate-Selective Membrane Electrode Based on Gallium(III)Tetraphenylphorfyrin," Electroanalysis, Vol. 12, No. 16, 2000, pp. 1282-1285. doi:10.1002/1521-4109(200011)12:16<1282::AID-ELAN 1282>3.0.CO;2-D

[4] E. M. G. Santos, A. N. Araújo, C. M. C. M. Couto and M. C. B. S. M. Montenegro, "Construction and Evaluation of PVC and Sol-Gel Sensor Membranes Based on Mn(III) TPP-Cl. Aplication to Valproate Determination in Pharmaceutical Preparation," Analytical and Bioanalytical Chemistry, Vol. 384, No. 4, 2006, pp. 867-875. doi:10.1007/s00216-005-0170-y

[5] S. S. M. Hassan, W. H. Mahmoud, M. A. F. Elmosallamy and M. H. Almarzooqi, "Nobel Ibuprofen Potentiometric Membrane Sensors Based on Tetraphenylphorfyrinato Indium(III)," Analytical Sciences, Vol. 19, No. 5, 2003, pp. 675-680. doi:10.2116/analsci.19.675

[6] J. H. A. Badr, M. E. Meyerhoff and S. S. M. Hassan, "Metallophorfyrin-Based Polymer Membrane Electrode with High Selectivity for 2-Hydroxybenzhydroxamate," Analytica Chimica Acta, Vol. 321, No. 1, 1996, pp. 11-19. doi:10.1016/0003-2670(95)00580-3

[7] E. M. G. Santos, A. N. Araújo, C. M. C. M. Couto and M. C. B. S. M. Montenegro, "Potentiometric Behaviour of Ion Selective Electrodes Based on Iron Porphyrins: The Influence of Porphyrins Substituents on the Response Properties and Analytical Determination of Diclofenac in Pharmaceutical Formulations," Journal of Pharmaceutical and Biomedical Analysis, Vol. 42, No. 5, 2006, pp. 535-542. doi:10.1016/j.jpba.2006.05.019

[8] O. Dinten, U. E. Spichiger, N. Chaniotakis, P. Gehring, B. Rusterholtz, W. E. Morf and W. Simon, "Lifetime of Neutral-Carrier-Based Liquid Membranes in Aqueous Samples and Blood and the Lipophilicity of Membrane Components," Analytical Chemistry, Vol. 63, No. 6, 1991,

\section{pp. 596-603. doi:10.1021/ac00006a009}

[9] J. Lin and C. W. Brown, "Sol-Gel Glass as a Matrix for Chemical and Biochemical Sensing," Trends in Analytical Chemistry, Vol. 16, No. 4, 1997, pp. 200-211. doi:10.1016/S0165-9936(97)00021-6

[10] W. Kim, S. Chung, S. B. Park, S. Ch. Lee, C. Kim and D. D. Sung, "Sol-Gel Method for the Matrix of Chloride-Selective Membranes Doped with FridodecylMethylammonium Chloride," Analytical Chemistry, Vol. 69, 1997, pp. 95-98. doi:10.1021/ac9604088

[11] W. Kim, D. D. Sung, G. S. Cha and S. B. Park, "Chloride-Selective Membranes Prepared with Different Matrices Including Polymers Obtained by the Sol-Gel Method," Analyst, Vol. 123, 1998, pp. 379-382. doi:10.1039/a705788a

[12] M. Mazloum, M. Salavati-Niasari, M. Khayat and S. M. Ghoreishi, "A Copper Ion-Selective Electrode with High Selectivity Prepared by Sol-Gel Coated Wire Techniques," Analytical and Bioanalytical Chemistry, Vol. 378, No. 6, 2004, pp. 1659-1665. doi:10.1007/s00216-003-2462-4

[13] S. Z. Yao, J. Shiao and L. H. Nie, "Potentiometric Determination of Penicillins with Ion-Selective Electrodes," Talanta, Vol. 36, No. 12, 1989, pp. 1249-1252. doi:10.1016/0039-9140(89)80058-X

[14] E. G. Kulapina, V. V. Baraguzina and O. I. Kulapina, "Ion-Selective Electrodes for Determining Penicillin Antibiotics in Biological Fluids and Pharmaceutical Forms," Journal of Analytical Chemistry, Vol. 59, No. 9, 2004, pp. 971-975. doi:10.1023/B:JANC.0000040704.24966.46

[15] M. S. Rizk, Y. M. Issa and A. F. Shoukry, "New Ampicillin Selective Plastic Membrane and Coated Metal Electrodes Based on Ampicillinium Phosphotungstate Ion Pair," Analytical Letters, Vol. 27, No. 6, 1994, pp. 10551065.

[16] N. V. Shvedene and S. V. Borovskaya, "Determination of $\beta$-Lactam Antibiotics by Potentiometry with Ion-Selective Electrodes," Journal of Analytical Chemistry, Vol. 58, No. 11, 2003, pp. 1208-1213. doi:10.1023/A:1027393608302

[17] G. J. Papariello, A. K. Muhkerji and C. M. Shearer, "Penicillin Selective Enzyme Electrode," Analytical Chemistry, Vol. 45, No. 4, 1973, pp. 790-792. doi: $10.1021 / \mathrm{ac} 60326 \mathrm{a} 032$

[18] I. S. Park, D. K. Kim and N. Kim, “ Characterization and Food Application of a Potentiometric Biosensor Measuring $\beta$-Lactam Antibiotics," Journal of Microbiology and Biotechnology, Vol. 14, No. 4, 2004, pp. 698-706.

[19] E. S. Gil and G. R. Melo, "Electrochemical Biosensors in Pharmaceutical Analysis," Brazilian Journal of Pharmaceutical Sciences, Vol. 46, No. 3, 2010, pp. 375-391.

[20] K. Gupta, et al., "Recent Advances on Potentiometric Membrane Sensors for Pharamaceutical Analysis," Combinatorial Chemistry \& High Throughput Screening, Vol. 14, No. 4, 2011, pp. 284-302.

[21] S. Alegret, J. Alonso, J. Bartrolí, A. A. S. C. Machado, J. L. F. C. Lima and J. M. Paulis, "Construction of Equipment for Potentiometric Determinations in Flow Analy- 
sis," Química Analítica, Vol. 6, No. 3, 1987, pp. 278-292.

[22] J. Alonso, J. Bartrolí, J. L. F. C. Lima and A. A. S. C. Machado, "Sequential Flow-Injection Determinations of Calcium and Magnesium in Waters," Analytica Chimica Acta, Vol. 179, 1986, pp. 503-508. doi:10.1016/S0003-2670(00)84500-6

[23] J. L. F. C. Lima, M. C. B. S. M. Montenegro and A. M. Roque da Silva, "A Phenobarbital-Selective Electrode without an Inner Reference Solution, an Its Application to Pharmaceutical Analysis," Journal of Pharmaceutical and Biomedical Analysis, Vol. 8, 1990, pp. 701-704. doi:10.1016/0731-7085(90)80106-Y

[24] J. L. F. C. Lima, M. C. B. S. M. Montenegro and A. M. Roque da Silva, "FIA Potentiometric Determination of Salicylate in Pharmaceutical Preparations with a Tubular Detector," Journal of Flow Injection Analysis, Vol. 7, 1990, pp. 19-33.

[25] European Directorate for the Quality of Medicines, "Directorate for the Quality of Medicines of the Council of Europe," European Pharmacopoeia, 4th Edition, 2002.

[26] IUPAC, Pure and Applied Chemistry, Vol. 53, No. 10, 1981, pp. 1907-1912. doi:10.1351/pac198153101907

[27] E. M. G. Santos, C. M. C. M. Couto, M. C. B. S. Montenegro, M. G. P. M. S. Neves, S. L. H. Rebelo, J. A. S. Cavaleiro and B. F. Reis, "Ion-Selective Electrodes Based on Metalloporphyrins for Gibberellic Acid Deter- mination in Agricultural Products," Analytical and Bioanalytical Chemistry, Vol. 375, No. 4, 2003, pp. 511-516.

[28] A. Caneiro, P. Fabry, H. Khireddine and E. Siebert, "Performance Characteristics of Sodium Superionic Conductor Prepared by the Sol-Gel Route for Sodium Sensors," Analytical Chemistry, Vol. 63, No. 22, 1991, pp. 2550-2557. doi:10.1021/ac00022a004

[29] U. Oesch, D. Amman, H. Pham, U. Wuthier, R. Zund and W. J. Simon, "Design of Anions-Selective Membranes for Clinically Relevant Sensors," Chemical Society Faraday Transactions I, Vol. 82, No. 4, 1986, pp. 1179 1186. doi:10.1039/f19868201179

[30] A. M. Pimenta, A. N. Araújo and M. C. B. S. M. Montenegro, "A Sequential Injection Analysis System for Potassium Clavulanate Determination Using Two Potentiometric Detectors," Journal of Pharmaceutical and Biomedical Analysis, Vol. 30, No. 4, 2002, pp. 931-937. doi:10.1016/S0731-7085(02)00474-0

[31] J. C. Miller and J. N. Miller, "Statistics for Analytical Chemistry," 2nd Edition, Ellis Horwood Ltd., Chichester, 1988.

[32] Analytical Methods Committee, "Recommendations for the Definition, Estimation, and Use of Detection Limit," Analyst, Vol. 112, 1987, pp. 199-204. doi:10.1039/an9871200199 